\title{
Isolation and Identification of Corynebacterium jeikeium from Synovial Fluid of a Joint Ill Affected Calf
}

\author{
Nair Aswathy ${ }^{1}$, P. M. Priya ${ }^{\text {* }}$, R. Ambily ${ }^{1}$, E. Niyas ${ }^{2}$, \\ Sudheesh S. Nair ${ }^{3}$, Rinsha Balan ${ }^{1}$ and M. Mini ${ }^{1}$ \\ ${ }^{1}$ Department of Veterinary Microbiology, College of Veterinary and Animal Sciences, \\ Mannuthy, Thrissur, Kerala, India \\ ${ }^{2}$ ULFFRDS, College of Veterinary and Animal Sciences, Mannuthy, Thrissur, Kerala, India \\ ${ }^{3}$ Department of Veterinary Surgery and Radiology, College of Veterinary and Animal \\ Sciences, Mannuthy, Thrissur, Kerala, India \\ *Corresponding author
}

\begin{tabular}{|l|}
\hline K e y w o r d s \\
$\begin{array}{l}\text { Calf, Corynebacterium } \\
\text { jeikeium, joint ill, } \\
\text { polymerase chain } \\
\text { reaction, rpo B gene }\end{array}$ \\
\hline Article Info \\
\hline $\begin{array}{l}\text { Accepted: } \\
\text { 24 August } 2019 \\
\text { Available Online: } \\
\text { 10 September } 2019\end{array}$ \\
\hline
\end{tabular}

A B S T R A C T
Corynebacterium sp. is a Gram-positive, non-motile and facultatively anaerobic bacilli present in the environment as ubiquitous organism. A 45 day-old Holstein Friesian calf from University Livestock Farm (ULF), Kerala Veterinary and Animal Sciences University, Mannuthy was reported with joint ill in both of its forelimbs. Using aseptic procedures, synovial fluid was collected from the right knee joint and inoculated on to blood agar and incubated at $37^{\circ} \mathrm{C}$ for 24 to $48 \mathrm{hrs}$ to isolate and identify the bacterial aetiology involved. Pin-point gray colonies with hazy haemolysis could be observed. On Gram's staining, Gram-positive bacilli with palisade arrangement could be observed. On sub culturing on to Potassium tellurite blood agar, black coloured colonies suggestive of Corynebacterium sp. was observed. Biochemical tests were performed both by conventional method and using Vitek system and the organism was identified as Corynebacterium jeikeium. On antibiotic sensitivity test (ABST), the organism was found to be highly sensitive to gentamicin, and highly resistant to ampicillin. For molecular confirmation, rpo B gene specific polymerase chain reaction (PCR) was performed and an expected 452 bp amplicons was obtained. Hence, the present case reports the isolation and characterisation of Corynebacterium jeikeium from a case of joint ill in a calf using conventional and molecular methods.

\section{Introduction}

Joint ill, a suppurative polyarthritis condition is one of the major causes of calf mortality in the age group of one week to one month (Bagga et al., 2009). As explained by Abdulla et al., (2015), the severe inflammation of the affected joints as a sequel of infection from umbilicus and its associated structures led to critical lameness in young farm animals. Commonly, the joint ill is observed in neonatal period due to unhygienic environmental conditions of the calving shed and improper umbilical cord asepsis (Radostitis et al., 2007). Some of the implied causes of joint ill in calves include 
Trueperella pyogenes, Fusobacterium necrophorum, Staphylococcus spp., etc. Other causes of synovitis and arthritis in cattle include Mycoplasma bovis, Brucella abortus, etc.

Corynebacterium spp. are ubiquitous organisms present in the environment, which are Gram-positive bacilli, non-motile and facultative anaerobic in nature. It is a common habitant in the mucous membrane and skin of the animals (Markey et al., 2013). The morphology has been described as a typical Chinese letter like arrangement (Indranil, 2013). Most commonly C. bovis isolates were observed to cause various pathological conditions like mastitis, polyarthritis etc. $C$. jeikeium was rarely isolated from bovine and has been reported to cause mastitis in cattle (Watt et al., 2000). So far, no published reports have found on the fact that it could cause arthritis in cattle. The present study reports the identification of $C$. jeikeium from a polyarthritis case.

\section{Materials and Methods}

\section{Collection of Synovial Fluid}

A 45 day-old Holstein Friesian calf (Fig. 1) from University Livestock Farm (ULF), Kerala Veterinary and Animal Sciences University, Mannuthy was reported to be suffering from joint ill in both of its forelimbs. Using aseptic procedures, the synovial fluid was collected from the right knee joint.

\section{Isolation and Identification of the Bacterial Agent}

The sample was inoculated on to 5 to $10 \%$ blood agar (BA) and incubated at $37^{\circ} \mathrm{C}$ both aerobically and micro aerobically for 24 to 48 hrs. Selective isolation was done by subculturing onto Potassium tellurite blood agar and incubated at $37^{\circ} \mathrm{C}$ for 24 to 48 hours.
Isolates were presumptively identified based on colony morphology, Gram's staining and biochemical tests and further confirmed by genus specific PCR. The biochemical tests include catalase, oxidase, IMViC (Indole, Methyl red, Voges- Proskauer and Citrate), urease and sugar fermentation tests. Vitek system was used for the confirmation of at species level.

\section{Molecular Confirmation by PCR}

The DNA was extracted by boiling and snap chilling method (Suresh et al., 2018). Molecular confirmation at genus level of the isolate was done by PCR using the primers targeting rpo B gene (Khamis et al., 2004). PCR assay was optimized with $12.5 \mu \mathrm{l}$ reaction mixture containing $3 \mu \mathrm{l}$ of DNA template, $6.25 \mu 1$ of $2 \mathrm{X}$ master mix (Taq Green Master Mix, Emerald), $1 \mu \mathrm{l}$ each of forward and reverse primers $(10 \mathrm{pmol} / \mu \mathrm{l})$ (Table- 1) and the rest of the volume is made by adding nuclease free water. The cycling conditions were as follows: initial denaturation at $95^{\circ} \mathrm{C}$ for $2 \mathrm{~min}$; 35 cycles of $94^{\circ} \mathrm{C}$ for $30 \mathrm{sec}, 51.4^{\circ} \mathrm{C}$ for $30 \mathrm{sec}$ and $72^{\circ} \mathrm{C}$ for $2 \mathrm{~min}$ and a final elongation step at $72^{\circ} \mathrm{C}$ for $10 \mathrm{~min}$. The PCR products were subjected to gel electrophoresis using $1.5 \%$ agarose with ethidium bromide as fluorescent dye and visualized using gel documentation unit (Biorad, USA).

\section{Antibiotic Sensitivity Test (ABST)}

The procedure of ABST was followed as per the guidelines established by Clinical and Laboratory Standards Institute (CLSI, 2015) with minor modification. The sensitivity of the isolate was tested in Muller Hinton agar against 15 selected antibiotics disc of HiMedia, Mumbai (Table-2). The antibiotics were selected based on the interest of the large animal practitioners to treat joint ill infected calves in studied farms. Measurement of the 
growth inhibition zone permitted the classification of each isolates as sensitive, intermediate and resistant according to data provided by Oxoid Ltd., Basingstoke, Hampshire, England and CLSI (2015).

\section{Results and Discussion}

Small, greyish white, hazy haemolytic colonies were observed on blood agar (Fig. 2). On Gram's staining, the isolate revealed Gram- positive bacilli with Chinese letter arrangement which was in agreement with Indranil, (2013). The black colony appearance on potassium tellurite agar (Fig. 3) and the other biochemical characters matched with the findings observed by Barrow and Feltham (1993) which supported for the confirmation of Corynebacterium jeikeium.

The isolates could ferment sugars like glucose and maltose but showed negative results for lactose, salicin, mannitol, sucrose, trehalose and xylose (Fig. 4). Based on the primary and secondary identification, the organism was identified as Corynebacterium jeikeium. Species confirmation was done using Vitek system.

The PCR was standardised for the identification of Corynebacterium spp. The amplicon size by targeting the gene rpo B obtained was 434 bp (Fig. 5) which was supported by the research done by Khamis et al., (2004). Corynebacterium jeikeium was isolated from the present study but Goodarzi et al., (2015) could isolate 20 per cent Corynebacterium bovis from the polyarthritic samples Corynebacterium spp. was observed as a common habitant of the skin and mucous membrane of animals by Markey et al., 2013. Watt et al., (2000) could isolate Corynebacterium jeikeium from mastitis affected cattle. Hence it could be concluded that the organism might caused joint ill in the present study as an outcome of cross contamination from the mastitis affected cattle.

Table.1 Details of the Primers

\begin{tabular}{|l|l|l|}
\hline Primer & Sequence & Amplicon size \\
\hline Rpo $\mathbf{F}$ & 5'-CGWATGAACATYGGBCAGGT-3' & \\
\hline Rpo R & 5'TCCATYTCRCCRAARCGCTG- -3' & 434 bp \\
\hline
\end{tabular}

Table.2 List of antibiotic discs and their concentration

\begin{tabular}{|c|c|c|}
\hline SI. No. & Name of antibiotic dises & Concentration \\
\hline $\mathbf{1}$ & Gentamicin (G) & $30 \mu \mathrm{g}$ \\
\hline $\mathbf{2}$ & Ceftriaxone (CTR) & $30 \mu \mathrm{g}$ \\
\hline $\mathbf{3}$ & Tetracycline(T) & $30 \mu \mathrm{g}$ \\
\hline $\mathbf{4}$ & Penicillin (P) & $10 \mathrm{Units}$ \\
\hline $\mathbf{5}$ & Cefalexin (CN) & $30 \mu \mathrm{g}$ \\
\hline $\mathbf{6}$ & Amoxyclav (AMC) & $30 \mu \mathrm{g}$ \\
\hline $\mathbf{7}$ & Enrofloxacin (EX) & $10 \mu \mathrm{g}$ \\
\hline $\mathbf{8}$ & Amoxycillin (AMX) & $30 \mu \mathrm{g}$ \\
\hline $\mathbf{9}$ & Streptomycin (S) & $25 \mu \mathrm{g}$ \\
\hline $\mathbf{1 0}$ & Amikacin (AK) & $30 \mu \mathrm{g}$ \\
\hline $\mathbf{1 1}$ & Ceftriaxone/ Sulbactam (CIS) & $30 \mu \mathrm{g}$ \\
\hline $\mathbf{1 2}$ & Ceftriaxone/ Tazobactam (CIT) & $30 \mu \mathrm{g}$ \\
\hline $\mathbf{1 3}$ & Cefuroxime (CXM) & $30 \mu \mathrm{g}$ \\
\hline $\mathbf{1 4}$ & Cefotaxime (CTX) & $30 \mu \mathrm{g}$ \\
\hline $\mathbf{1 5}$ & Ampicillin & $10 \mu \mathrm{g}$ \\
\hline
\end{tabular}


Fig.1 Calf showing inflammation on both the knee joint

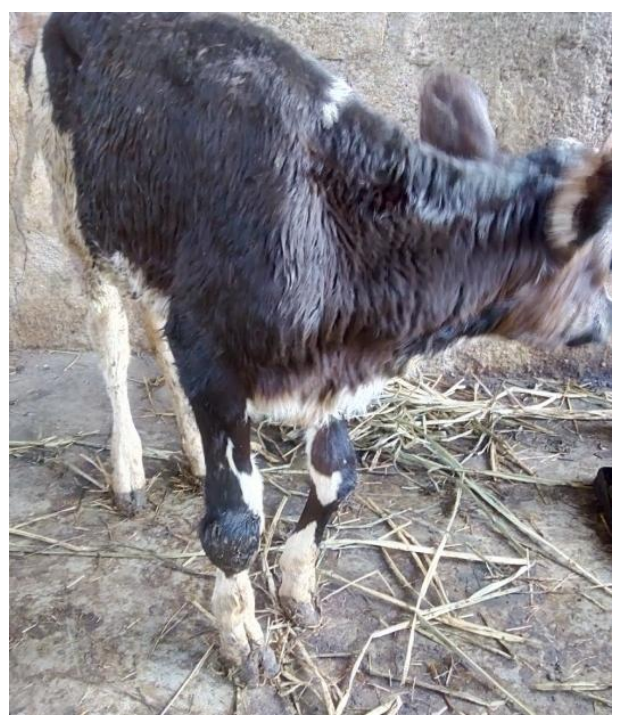

Fig.2 Greyish white colonies with hazy haemolysis on BA

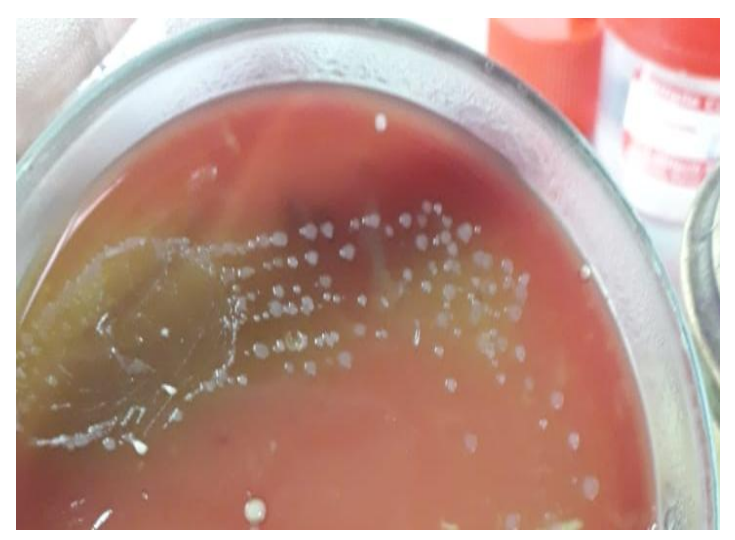

Fig.3 Black coloured colonies on Potassium tellurite agar

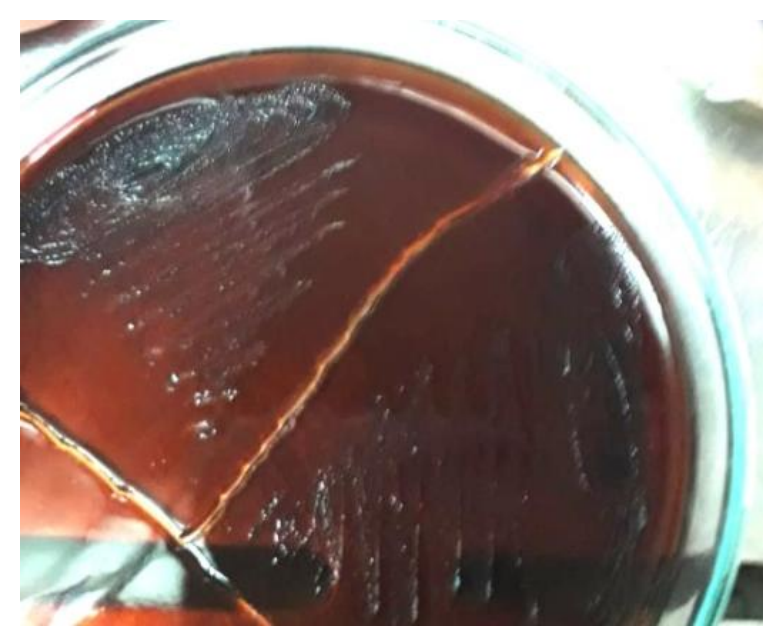


Fig.4 Sugar fermentation tests of Corynebacterium jeikeium
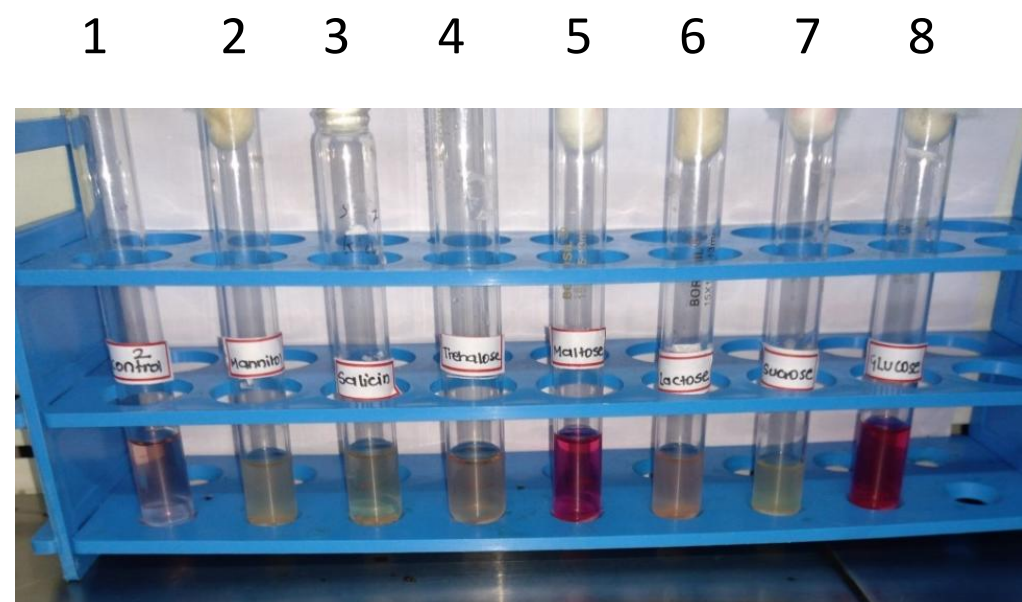

1) Control; 2) Mannitol; 3) Salicin; 4) Trehalose

5) Maltose; 6) Lactose; 7) Sucrose; 8) Glucose

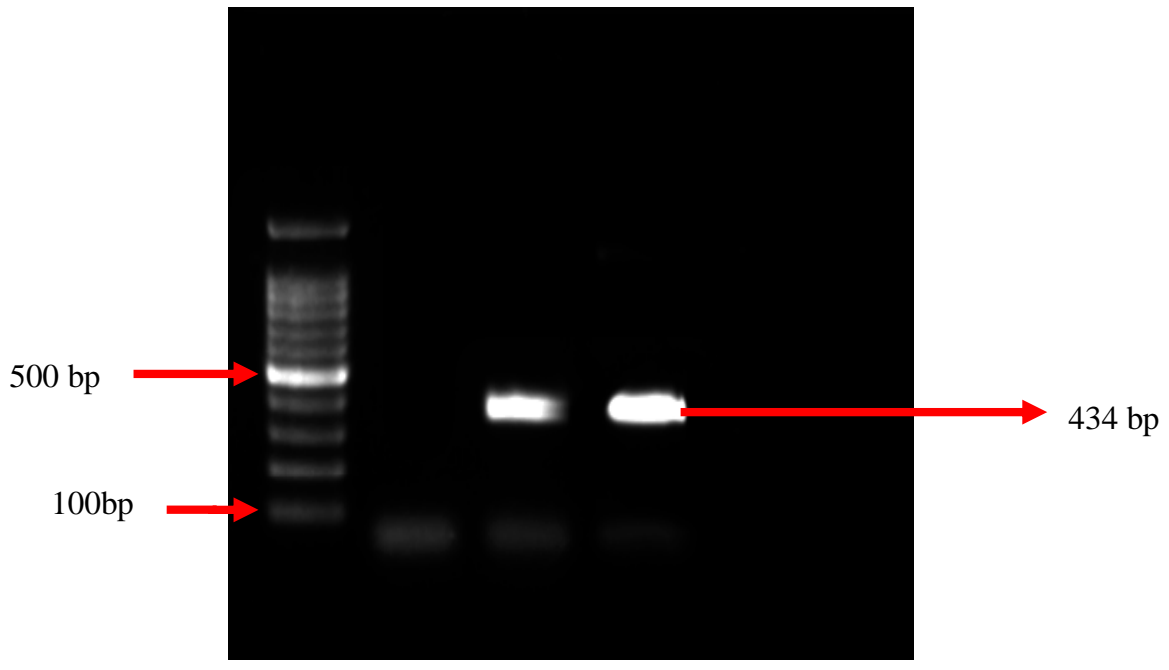

Fig. 5 PCR amplification of $r p o B$ gene of

Corynebacterium spp.

Lane 1- 100 bp Ladder

Lane 2, 5 and 6- Negative isolates

Lane 3 - Positive control

Lane 4- Positive isolate

The results of ABST revealed the organism was sensitive to gentamicin, tetracycline, enrofloxacin, amikacin and streptomycin; intermediate sensitive to penicillin-G, ceftriaxone/ tazobactam, cefuroxime and cefotaxime and resistant towards ampicillin, ceftrixaone, cefalexin, amoxyclav and amoxycillin.
Corynebacterium jeikeuim is rarely isolated from bovine but reports have found on that isolates could cause mastitis in cattle but rare or almost nil reports have found on the fact that it could cause arthritis in cattle. The isolation of Corynebacterium jeikeium from a case of joint ill in a calf using conventional and molecular methods is highlighting the 
importance of maintaining calving shed hygiene, naval asepsis and timely treatment of infected calves.

\section{Acknowledgement}

The authors are thankful to the Dean, College of Veterinary and Animal Sciences, Mannuthy for providing necessary infrastructure for the study.

\section{References}

Abdullah, F. F. J., Sadiq, M. A., Mohammed, K., Tijjani, A., Abba, Y., Chung, T. L. E., Adamu, L., Osman, A. Y., Lila, M. A. M., Haron, A. W. and Saharee, A. A. 2015. A clinical case of Navel ill in a calf: Medical management. Int. J. Livestock Res. 5: 103-108.

Bagga, A., Muralidhara, A. and Ravindarnath, B. M. 2009. Joint and navel ill association and its treatment in five calves - A clinical study. Intas Polivet. 10: 204-206.

Barrow, C. I. and Feltham, K. K. A. 1993. Co-identification of medical bacteria. ( $2^{\text {nd }}$ Ed.). Cambridge University Press, USA, 331p.

Goodarzi, M., Khamesipour, F., Mahallati, S. F., Dehkordi, M. K. and Azizi, S. 2015. Study on prevalence of bacterial causes in calves arthritis. J.Asian Res. Publishing Network. 10: 206-212.

Indranil, S. 2013. Veterinary bacteriology. $\left(1^{\text {st }}\right.$

Ed.). New Indian publishers, New Delhi, 377p.
Jalal, M. S., Dutta, A., Islam, K. M. F., Sultana, J., Sohel, M. S. H. and Ahad, A. 2016. A study on the prevalence and etiology of joint ill in calves of cross breed dairy cattle in six dairy farms of Bangladesh. Res. J. Vet. Pract. 4: 66-70.

Khamis, A., Raoult, D. and Scola, B. 2004. rpoBGene sequencing for identification of Corynebacterium species. J. Clin. Microbiol.19: 3925-3931.

Markey, B. K., Leonard, F.C., Archambault, M., Cullinae, A. and Maguire, D. 2013. Clinical Veterinary microbiology. (2nd Ed.). Elsevier, St. Louis, 1476p.

Radostits, O. M., Gay, G. C., Hinchcliff, K. W. and Constable, P. D. 2007. Veterinary Medicine-A Text book for the Diseases of Cattle, Sheep, Pigs, Goats and Horses. (10 ${ }^{\text {th }}$ Ed.). Saunders Elsevier, St. Louis, 645p.

Suresh Y, Subhashini N, Kiranmayi CB, Srinivas K, Ram VP, Chaitanya G. 2018. Isolation, Molecular characterization and antimicrobial resistance patterns of four different Vibrio species isolated from fresh water fishes. Int. J Curr. Microbiol. App. Sci. 2018. 7(07):3080-3088.

Watts, J. L., Lowery, D. E., Teel, J. F. and Rossbach, S., 2000. Identification of Corynebacterium bovis and other coryneforms isolated from bovine mammary glands. J. Dairy sci. 83(10): 2373-2379.

Wayne, P. A. 2015. Methods for dilution antimicrobial susceptibility tests for bacteria that grow aerobically. In: CLSI guideline. (10 ${ }^{\text {th }}$ Ed.). USA, 1-86 p.

\section{How to cite this article:}

Nair Aswathy, P. M. Priya, R. Ambily, E. Niyas, Sudheesh S. Nair, Rinsha Balan and Mini M. 2019. Isolation and Identification of Corynebacterium jeikeium from Synovial Fluid of a Joint Ill Affected Calf. Int.J.Curr.Microbiol.App.Sci. 8(09): 2875- 2880.

doi: https://doi.org/10.20546/ijcmas.2019.809.330 